\title{
On-Foot Hyperlocal Delivery - An Overview, Challenges, and Opportunities: Case Studies in Korea
}

\author{
Bernardo Nugroho Yahya ${ }^{1^{*}}$
}

\begin{abstract}
During the Covid19 pandemic, many local businesses were struggling to survive. With the rising of click and collect solutions, business strives to survive by offering pick-up points and maintaining the social distance policy. The demand for goods and services of customers are met instantly from the local offline shops via digital platform. Meanwhile, local businesses in a specific geographical area are still striving from the hard times due to least popularity and competitivenes in the services such as delivery. Hyperlocal delivery comes into the logistics industry to meet the issues from local businesses. While the hyperlocal delivery terminology is still new, there have been some real world practices. This study attempts to define the hyperlocal delivery and explore multiple case studies to analyze the on-foot delivery as a rising of quick commerce in the gig economy. The multiple case studies will take place on the on-foot hyperlocal delivery business models in South Korea. The overview of the on-foot hyperlocal delivery will be described in three components of analysis; strategy, customer \& market, and value added model. At the end, some research challenges and opportunities are presented to show how the research communities can contribute to the field.
\end{abstract}

Keywords: Hyperlocal delivery, on-foot delivery, gig economy, last mile logistics, quick commerce.

\section{Introduction}

The Covid19 pandemic has caused a rising in the demand for goods' deliveries. The stay-at-home policy has enforced many business organizations to re-engineer the business models to get closer to customers. The rapid shift from many businesses has enforced last-mile logistics companies to do delivery in quick, flexible, safe, and efficient [1]. Last mile logistics (LML) refers to the final step of the delivery process from a distribution center or facility to the end-user. Commonly, the final mile of delivery can range from a few blocks to 50 or 100 miles. Most often, last mile logistics involves the use of parcel or small package carriers to deliver products to consumers. The business in last mile logistics have been widen from 3PLs (Third party logistics) to 4PLs (Fourth party logistics) with specialized companies and even small local couriers and startup. The future delivery, or some mentioned as urban delivery services, may be driven with the concept of sharing economy, digitalization and connectivity of transportations and logistics, and the autonomous vehicles and deliveries [2].

According to the survey from a company, the policy of social distancing caused the increment on delivery orders [3]. In Korea, the number of orders increased about $15 \%$ during the $2^{\text {nd }}$ wave of Covid 19 in the mid

\footnotetext{
${ }^{1}$ Industrial and Management Engineering Department, Hankuk University of Foreign Studies. Oedae-ro 81, Yongin, Gyeonggi 17035, Republic of Korea. Email: bernardo@hufs.ac.kr

* Corresponding author
}

of August 2020. And the order volume on weekends (the end of August 2020) surged about 33\% in comparison to the previous week of the mentioned period. The delivery volume increase while the delivery riders are scarce. While the delivery companies attempted to look for more delivery agents by increasing the daily wages to almost double, it became a burden for the small business owners since it increases the delivery costs and finally cause a high cost on the product (e.g., food from a restaurant). Hence, some startups began an idea to utilize the local communities, noted as Hyperlocal business model.

According to the survey from a company, the policy of social distancing caused the increment on delivery orders [3]. In Korea, the number of orders increased about $15 \%$ during the $2^{\text {nd }}$ wave of Covid 19 in the mid of August 2020. And the order volume on weekends (the end of August 2020) surged about 33\% in comparison to the previous week of the mentioned period. The delivery volume increase while the delivery riders are scarce. While the delivery companies attempted to look for more delivery agents by increasing the daily wages to almost double, it became a burden for the small business owners since it increases the delivery costs and finally cause a high cost on the product (e.g., food from a restaurant). Hence, some startups began an idea to utilize the local communities, noted as Hyperlocal business model.

Hyperlocal business model refers to the services pertaining to a specific local geographic area. The business model has favored the growth of online local news services and the journalism from and within 
communities [4]. The idea of the business model in the local news is shifted toward the logistics by promoting the local people to be the delivery person in the local geographic area. In the broad domain, the concept such as Mobility-as-a-Service (MaaS) and Deliveryas-a-Service (DaaS) have been around. However, both concepts cover in more global regional. Hyperlocal business model, called as the hyperlocal delivery, will become a trend to deal with the scarcity of delivery agents in the local community. The crowd participation becomes obvious and local economy is likely to have some effects with the hyperlocal delivery. While the impact is obvious, there is still a necessity to clearly understand the business model and the role in the community.

This study attempts to explore the hyperlocal business model in the domain of logistics. The hyperlocal delivery, as noted in some literatures, may come into the real world to cope with the Covid 19 pandemic in some respects. In addition, the business model will become a new way of logistics in the near future. The novelty of studying the enabling role in the new business model may enforce the business society to enlarge the impacts and the academic society to improve the intelligence aspects. Although many old businesses collapse due to the Covid19 pandemic, there are also some success stories from new startups. Hence, it raises a question on how the new business model, that is, hyperlocal delivery can sustain. This study provides an overview on on-foot hyperlocal delivery. The methodology used in this study is a desk research based on the common sources from the relevant online databases, company official sites, and trade associations. For the analysis, this study starts with the exploration of the current market trends and some major concepts in LML such as pick-up points and click-and-collect. Subsequently, the discussion takes place on hyperlocal delivery with multiple case studies and utilizes an analysis framework to see the challenges and opportunities. In prior to the discussion, three case studies of hyperlocal delivery in South Korea will be addressed.

\section{Methods}

\section{Current Market Trends and Major Concepts in Hyperlocal Delivery}

Studies by PWC mentioned that $75 \%$ consumers around the world desire more human interaction and $65 \%$ of U.S. consumers find a positive consumer experience to be more influential than advertising [5]. In addition, the innovations in the urban logistics include various forms of pick-up points and click-andcollect solutions due to the rapid rise technology and algorithms for instant deliveries (on-demand deliveries within less than two hours) [6][7].
Pick up points are the main alternative to home delivery with an advantage to offer the end-customer more flexibility. Some example of the pick-up points is automatic lockers (e.g., safety deposit box) where a package is dropped before being collected by the customer at the time suits them. Based on a survey [8], the majority of purchasers $(75 \%)$ said flexibility was the most important factor when considering delivery options, while $42 \%$ said that being able to choose a pick-up point or an automatic locker was important. Some competitive pick-up points network in all over Europe are post offices, businesses, petrol stations, shopping centers, etc. Meanwhile, American, Japan, Korea have almost similar pick-up points, that is mostly at convenience stores. [9]

Click-and-collect solutions appear to be an alternative solution for e-retailers and consumers. The concept is customer could collect their orders in any pre-defined points. The pre-defined points can increase customer's convenience and satisfaction in the aspect of cost when the price to collect is lower than the home delivery. In addition, the solution could benefit to reduce transportation cost from the company and missed deliveries which the service providers allow 24 hours' logistics operations. Customers benefit the solution in term of speed, low cost, and convenience of the fulfillment model. With the concerns of social distancing in the Covid19 pandemic, the solution offers on how to avoid shopping in crowded areas and still enjoy the advantage of local retail locations.

The solution using click-and-collect is not a new concept. However, the Covid19 pandemic showed a massive spike in demand and turned it into one of the hottest retail trends. In 2017, the Click and Collect Retail Consumer Preference Study published that nearly one third of shoppers made an online purchase and subsequently picked their order up at a store during the 2016 holiday season. The statistics in 2020 showed that there is an increment over $554 \%$ YOY in May using in-store pickup. The key factor of this solution is ( $76 \%$ of the shoppers mentioned) about saving the shipping costs.

Hyperlocal business model refers to the services pertaining to a specific local geographic area. The business model has favored the growth of online local news services and the journalism from and within communities [4]. Due to the ongoing Covid19 pandemic, the online deliveries of groceries and other essential items are rising. Instead of visiting local shops, people tend to order online. When it comes to the logistics, it raises the hyperlocal delivery [10]. The main point of hyperlocal delivery is to connect people with the local business with technology such as GPSlocation data and wireless internet availability. Commonly, the hyperlocal delivery is an extension of LML with very short distance, that is a few miles. The newcomer on on-foot hyperlocal delivery attempts to shorten the distance into 1 mile $(1.5 \mathrm{~km})$. 
In USA, there are some popular hyperlocal delivery app such as DoorDash or GrubHub (for restaurant) and Instacart or Peapod (for groceries). With the existing open-source e-commerce frameworks such as Magento, WooCommerce, OpenCart, PrestaShop, CS-Cart, there are many customized order management systems (OMS) for building business or ecommerce platforms. In Europe and Asia, there are some applications on hyperlocal delivery based on the crowdsourcing, called as crowd-logistics [11][12]. The crowd-logistics exist due to the necessity to deliver products in the last mile distance by elaborating the crowds surrounding the areas. While crowd-logistics exist in the communities, there is still lack of definetions on how to promote the crowds as a business stakeholder. This study focuses on the on-foot hyperlocal delivery which emphasizes the differrent between the common online delivery and the LML concepts in terms of three components: strategy, customer \& market, and value (added) creation component.

\section{Thriving the Gig Economy}

A gig economy is a free market system in which temporary positions are common and organizations hire independent workers for short-term commitments [13]. The connections proposed for thriving the gig economy consists of four aspects: place, routines, purpose, and people. Although the four aspects are inter-correlated, only three aspects (i.e., routines, purpose, and people) may show the importance since the first aspect, that is place, is already set in the local geographical area of the hyperlocal delivery.

Routine (daily) behavior defines the structure of and influences almost every aspect of people's lives. Routines (daily) behavior are defined by frequent actions of people in different situations [1]. By understanding the routines (daily) behavior, one can interpret the effectiveness of his behavior and support potential behavior changes for better productivity. Some key domains that need the human routine behavior include context-aware services [2], e-health [3], [4], smart offices [5], robot imitation learning [6], [7], unusual behavior [8], [9], consumer purchasing behavior [10], smart walk [11], etc.

This routine behavior has also been done by people to enhance performance. For example, elite athletes, scientific geniuses, popular artists, and everyday workers use routines to enhance focus and performance. The professionals and ordinary people tend to rely on the routine behaviors in the same way. It should be noted that some routines improve people's workflow. Other routines, usually involving sleep, meditation, exercise, personal care, etc. will also work to improve performance. By considering the routine behavior of ordinary people, some businesses attempt to associate the routine of ordinary people with economy activity, such as local delivery.

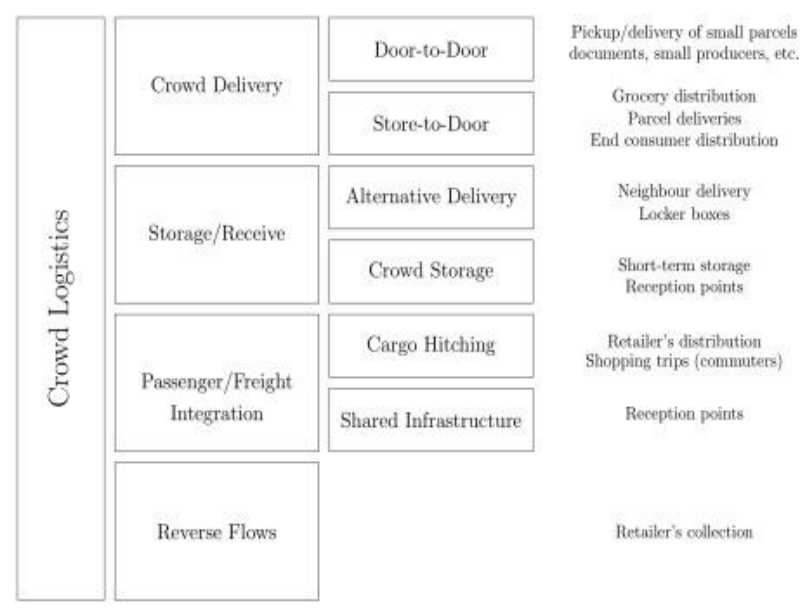

Figure 1. Crowd Logistics concepts and applications [12]

Purpose is a bridge between a person personal interest and motivation and the need in the world. For example, a person who is doing exercise (e.g., walking, running) can also deliver a good to another person. Although many purposes are dealing with non-monetary compensation, the monetary rewards become an extrinsic factor for a person to participate in a crowdsourcing project [11]. The purpose of a person to participate in a gig economy in the Covid19 pandemic becomes obvious on the economic reasons.

People is related to the crowd. The concept of crowdsourced delivery has been around [14][12]. While there are other sub-disciplines such as crowdfunding, crowd-voting, or crowd-searching, the use of crowdsourcing in logistics becomes important. The crowdsource logistics refer to services that engage the crowd and leverage the concepts of crowdsourcing applications in various ways. Potential advantages and challenges of logistics with the crowd, referred as crowd-logistics, would be further discussed (Please refer to Figure 1). The inter-correlated between crowd-logistics and the aspects on gig economy has enforce the on-foot hyperlocal delivery. While the general concept has been around (i.e., store-to-door), the implementation of on-foot hyperlocal delivery on the real world is still rare. This study attempts to explore some case studies of on-foot hyperlocal delivery in Korea. In addition, the concepts of crowdlogistics and some analysis dimensions are adopted to see the challenges and opportunities of this business model.

\section{Analysis Framework}

This research utilized the interaction between theory and the empirical world with deductive research. Deductive research is conducted in three stages: desk research on existing theory, multiple case studies on the empirical world, and analysis on the interaction between theory and the empirical world. Although the general deductive approach is not as strong as some other analytic strategies for model development, 
it provides a straightforward approach to derive the context of analysis.

The desk research on existing theory explores the current LML in correlation with the gig economy. The key components of the latest LML and the gig economy would be the theoretical basis of this study. The empirical world exploration is based on the multiple case studies. The case study is a research method to understand the dynamics of single settings [15]. This study attempts to perform multiple case studies to understand the rationale of the on-foot hyperlocal delivery. Research through multiple case studies requires establishing a clear research protocol that ensures reliability and generalization via sample selection. The sample selection is done in the Korean language in Korea search engine, that is Naver. The details explanations on sample selections are described in the later section.

The extracted case studies would then be analyzed with the theory based on the three relevant components: strategy components, customer and market components, and value (added) creation component [16]. Strategy component aims to discuss the activities of a company in order to persist on the market by uniting the business vision, mission, and goals. Customer \& market components emphasize the customer profile, market structure, and the revenue model of the business model. Value creation components aim to provide value added to the existing process model. Afterward, the analysis from those components would be a discussion on how the on-foot hyperlocal delivery might sustain for the future business model.

\section{Results and Discussions}

\section{Case Studies of On-Foot Hyperlocal Delivery in South Korea}

Sample selection was conducted using the keyword neighborhood delivery (in Korean letter) in the Korean search engine, called Naver. First, one of the rising startups in the Covid19 pandemic, that is Udeal (the name of Neighborhood Delivery app), was on the search list. By looking at the latest news about the startup, there are similar applications to deal with Neighborhood delivery. Other applications are listed and evaluated based on the popularity.

Neighborhood Delivery is a startup which has been started in the period of Covid19 pandemic [17]. The operation of the platform is to allocate any order from an app called "Yogiyo" to get delivered to the customer via another mobile app, called Udeal. The transportation method focusses on walking and the delivery person candidates are college students, housewife, and retirees. Since the transportation method is only available with walking, the maximum weight should not exceed $5 \mathrm{~kg}$. Lead by one of the fast- growing convenience stores in Korea, that is GS25, this app has recruited 18,000 people within a month after the app launched.

The starting process of this app is an order. When there is an order, there will be an alarm in the delivery person's phone. The delivery person can see the approximate of current location, pickup location, and delivery location. If the delivery person decides to proceed the selection, the order will be assigned to the person. The convenience store will prepare the products and the default delivery cost fee is 2.800 $\mathrm{KRW}$ and $1.000 \mathrm{KRW}$ is paid for the current event. If there is nobody receives the assignment, the convenience store will consign the order to the general delivery person after the preparation completes. The details of the delivered item are unknown. But there would be other details such as the weight categories such as "heavy", "break cautions", and "hot cautions". The detail delivery location will be available after you visit the convenience store. Due to the Covid19 pandemic, there should be non-face-to-face meeting between the delivery person and the customer. Hence, there will be a complete button after the delivery person taking a picture.

Following the Udeal, the similar application by MG Playing has been established to deal the same issue of delivery. The only different is the vendor who provides the service, which is CU, another convenience store brands in South Korea. The application from MG Playing, called Dobo60, provides an official website for deliverer's registration [18]. Once the person is registered as the delivery person, he/she will get the notification as the Udeal performed.

Another player in the convenience store, that is Emart24, attempts to segment the market to the university students [19]. Although the application is under testing, the memorandum of understanding (MoU) between the company (i.e, Emart) and the students' cooperation agency have been made. The students' cooperation agency has their own affiliation to deal with the logistics for school distribution. By the new MoU, some of the products would be from the Emart, which is one of the giant's grocery stores in South Korea. The company has declared that the focus of the convenience store would help university students. In other word, the available university students would be the on-foot deliverer to the other university students who need the grocery products.

\section{An analysis on Hyperlocal Delivery}

The strategy of on-foot hyperlocal delivery is twofold: improve the delivery performance (i.e., speed) and empower local communities to support local economy. One of the issues on the delivery is the fast response and delivery. There are three categories on the delivery systems; self-delivery, professional delivery, 


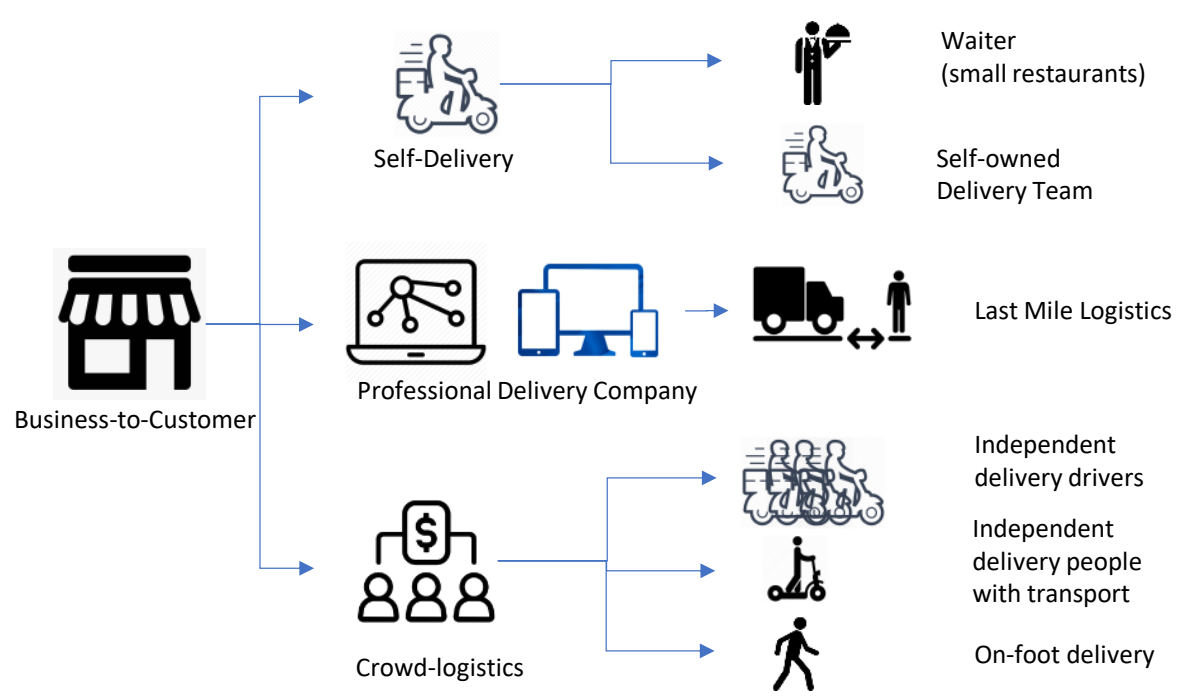

Figure 2. Business-to-customer delivery systems

and crowd-logistics (see Figure 2). Self-delivery system is usually provided by local restaurants, either by the waiter or the self-owned delivery team (KFC, McDonald, etc.). Professional delivery exists in the online shopping and delivery systems to send groceries in some amount with some distances between $50-100$ miles. The sharing economy has encouraged many startups to build applications to gather crowds for being independent drivers. People believed that motorized deliverer could transport the products (e.g., food, groceries, etc.) in efficient ways. As a matter of fact, the Covid19 pandemic has raised the number of online shoppers and there were limitations on the number of delivery person. Meanwhile, many of people have difficulties to get motor licensed, some people tend to be the independent drivers with other type motorized transport mode such as scooter, bike, etc. The on-foot delivery is one of this type whereby the deliverer needs no transport mode.

According to the Das [20], the manpower allocation for delivery services can be classified into four (4) strategies (see Figure 3). Since most of the online delivery business have full-time delivery person, some businesses attempt to apply the strategy to utilize part-time delivery person. The combination of Quadrant III (Prudent strategy) and IV (Rationale Strategy) are suitable to address the limitations of the number of delivery person. However, the part-time delivery person is required to set a contract with the business. In this sense, it is complicated to handle the flexibility. The crowdsourcing is the alternative solution to increase the capability of delivery performance. To avoid dissatisfaction results, online platform service providers set a rationale delivery time to the customers for store-to-customer. In most applications, the online platform estimates about 40 minutes for the delivery time. Meanwhile, in the last mile delivery,

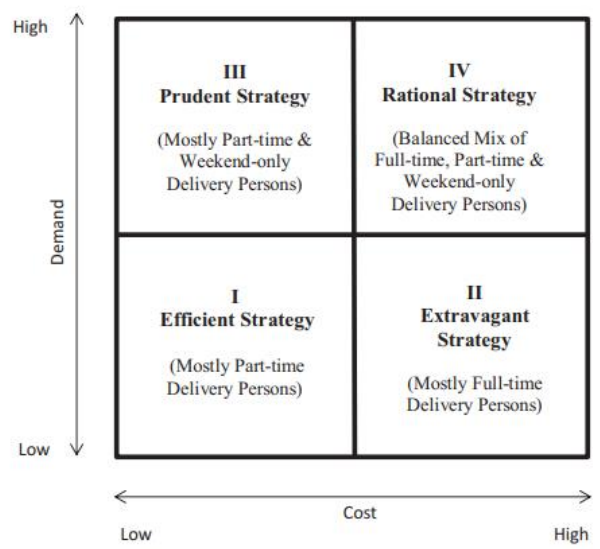

Figure 3. Framework of hiring strategy for deliverer [20]

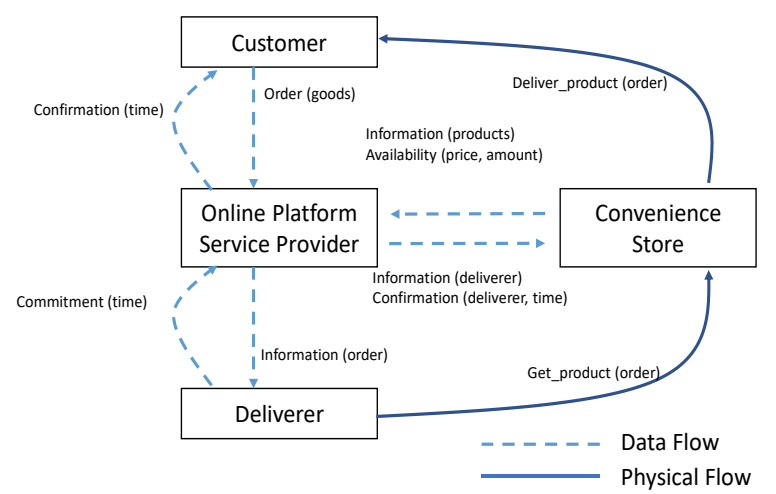

Figure 4. Online delivery communication network (data flow and physical flow)

the on-foot hyperlocal delivery could improve the delivery performance by reaching almost half from the standard delivery time, that is about 21 minutes. The other strategy of on-foot hyperlocal delivery is to empower the local communities; hence, the range of delivery distance is set to $1.5 \mathrm{~km}$ ( 1 mile $)$ as the maximum. 

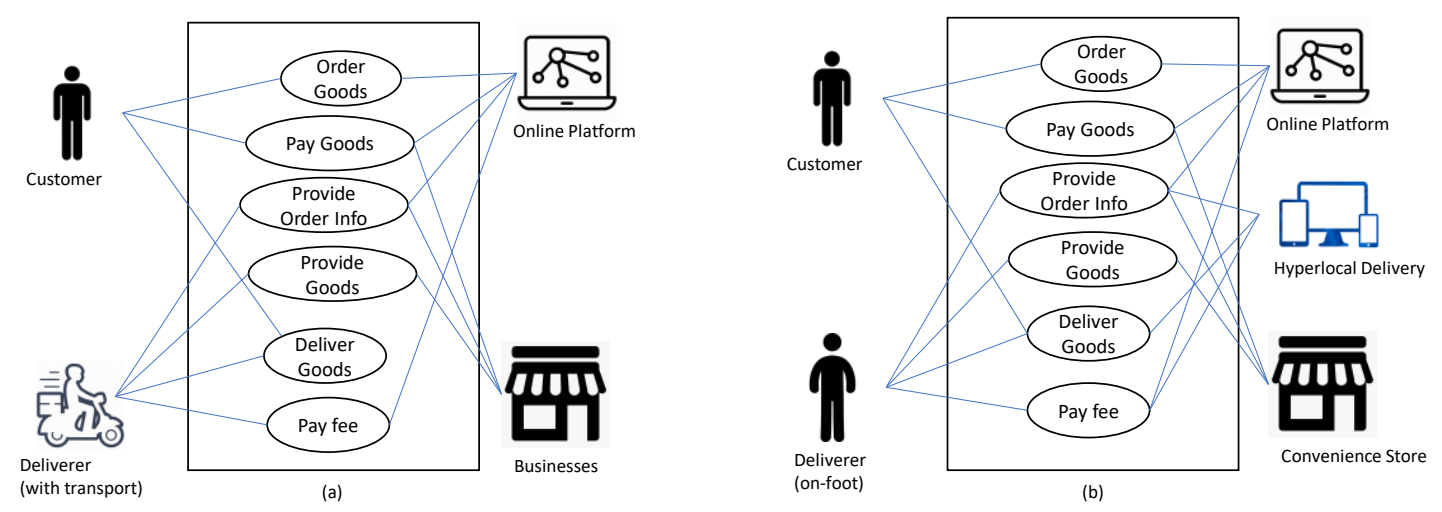

Figure 5. Use case of general hyperlocal delivery (a) and on-foot hyperlocal delivery (b)

In the customer \& market components, the on-foot hyperlocal delivery business model comprises of threefold: customer model, market offer model, and revenue model. The customer model discusses the customer profiles. The current business model fits with the customer who frequently use convenience stores. There are about 40,000 stores in Korea with an annual rate between 3,000 and 5,000 [21]. The social distancing policy cause significant sales decrement in the convenience stores. The fierce competitions (one of the aspects of market offer model) among the brands of convenience store impose the stakeholders to find creative ways to maintain the profit. To cope with the customer model and the market offer model, a revenue model should be set for a sustainable business model. The stay-at-home economy boost the growth of on-foot hyperlocal delivery by attracting local person who get economic problems due to the Covid19. The unemployed person attempts to find any possible job. Additionally, some persons who would like to get pocket money are the alternative possible target. Once the Udeal comes to the marketplace, there are significant interest from the local communities. A few months after the upcoming Udeal, the competitor (i.e., MG Playing) comes with similar ideas but different revenue model. This trendy business attracts the other competitor (i.e., Emart24) to enter the battle with different customer \& market components. While Udeal attempts to attract housewife and students, MG Playing seeks additional customer model, that is senior person. On the other hand, Emart24 is likely to focus on university students as the customer model. For the revenue model, both Udeal and MG Playing have slightly different schemes on the incentive models whereas the former offers better incentive (i.e., monetary benefits) than the latter. In the near future, on-foot hyperlocal delivery can be replaced with an alternative to the new concept of using robot delivery (e.g., drones, etc.).

Value added components address the value generation, resource acquisition, and financial model. The incentive in terms of the monetary benefits is small. The delivery man is expected to get 2,800 - 3,200 Korean Won per delivery (in the case of Udeal). Hence, the value generation is commonly non-monetary benefits such as health purpose. The resource acquisition conveys the problem on manpower when there is an order. The number of registrants on Udeal reached 12,000 deliverers for the first month after its launching. It shows the high interest of this new business model. In regard to the financial model, the deliverer would not get the incentive right after the delivery process completes. As a fact, Udeal is likely to pay weekly on every Thursday. Meanwhile, there is no guarantee to do many delivery services since it depends on the local area population density. Hence, the MG Playing has a slight improvement on the financial model in comparison to Udeal so that many local people change their preferences from Udeal to MG Playing to get more benefits as being a deliverer.

It should be noted that the on-foot hyperlocal delivery can be a combination of online platform (e.g., e-commerce), food business, and delivery. In the case of onfoot hyperlocal delivery in Korea, it still emphasizes the crowd participations on consumer goods from convenience stores. Since the hyperlocal delivery adopts the sharing economy concepts, the network between two customer profiles (i.e., customer side and the deliverer side) is essential. The deliverer network may consist of freelancers and courier, express, and parcel (CEP) service providers who execute the actual service. The online platform service provider acts as mediator between these two networks, as illustrated in the communication diagram (see Figure 4). To see the specific purpose of the on-foot hyperlocal delivery, the use case is represented in Figure 5.

There are limited applications which focused on delivery only. There are various shopping and delivery applications in South Korea such as Yogiyo, Baemin, Baedal Tong, Coupang Eatz, Wemape-O, etc. Those applications established their phone-based applications and recruit deliverers to their companies, either full-time or part-time. Since there are many customers' demands on the local while no deliverer in the urban side, some local delivery apps rise. For example, a company called Saengak-dero attempts to utilize local person and build a local office to educate and allocate deliverer to the proper local business applications. It should be noted that there are many local 
business applications rely on the brick-and-mortar concepts. It means the customer should visit and experience in the local store rather than enjoying the delivery. In the Covid19 pandemic, the local business has difficulties to recruit deliverer due to the high fix cost while the local business needs to embrace the social distancing policy. As a result, the local delivery app is one of the solutions to the local business to survive with the online manner.

\section{Discussions}

The following benefits of the business model can be observed: a new level of customer participation, additional earning opportunities, reduction of transport costs, also for the customer (by bringing along) flexible service and job opportunities. Aligning with the thriving of gig economy, the implication of the on-foot hyperlocal delivery (i.e., purpose) is to maximize the social capital while minimizing the natural capital. The social capital refers to the people participation on the business aspects and there no requirement to have motorcycle for being a delivery person. The Covid19 pandemic has given a great impact on the unemployment in Korea. This walking delivery solution is gaining interest as a part-time job to earn pocket money. The delivery man is expected to get 2,800 - 3,200 Korean Won per delivery. Although different applications provide different scheme of incentive, the economy impact of the on-foot hyperlocal delivery is significant to the local communities such as students, housewife, and people who needs flexible working hours. In addition, the current on-foot hyperlocal delivery is available with no transportation or requireed equipment. The natural capital refers to the utilization of transportation modes such as motorcycle for the deliveries. With onfoot delivery, the use of motorcycles would be less and directly lower the pollution effects which minimize the natural capital. The efficient of urban space is indirectly manageable due to the no usage of motorcycle. When there is no motorcycle, there is a guarantee that the urban life is healthier and more safety. Therefore, the citizen mobilizations make a difference to build the sustainable community development.

The other significant issue on the delivery is the users (i.e., people). There are two sides of users: deliverer and customer. In term of deliverer, the delivery person in the common delivery service is required to have a driving license to drive the motorized transport. In Korea, there is a new enforced regulation on the use of e-scooter to prevent the rising accidents due to the unskilled users. To use motorcycle (or e-scooter), a deliverer should apply the driving license as well. Therefore, there are limitations on the number of deliverer while the number of online shoppers were rising during the Covid19 pandemic. The on-foot hyperlocal delivery is a promising application in the mid of Covid19 pandemic. In addition, the business model seems sustainable due to the nature of gig economy, which allow people to have a temporary job regardless the place. While some people have routines such as health exercise, they can apply as a deliverer on this business model to obtain the economic benefit (i.e., purpose).

About the routines, this study emphasizes the technology being used by most likely all the people around the world, that is smartphone. People used smartphone in almost all aspects on their daily activities. Regarding technology, the three case studies on on-foot hyperlocal delivery are using installed-based applications on smartphone. With respect to the customers, it is rigorous to adopt one application to another. The three case studies mentioned in the previous chapter provided by different applications. Hence, the customer who would like to use the services need to fit with the requirements. In other word, users, in this case deliverer, need to install an application to receive order notice. The use of install-based applications would ease the service providers to detect the current location. However, the giant technology companies in Korea attempt to enter this market. Kakao and Naver are two giant technology companies that come into the competitions. Kakao is originally an online messenger company. Currently, it becomes a giant technology company due to the wide used of the KakaoTalk applications among the Korean people. In addition, there are many applications which connect to the daily life such as KakaoPay (i.e., payment), KakaoGift (i.e., coupons), etc. The new business of Kakao, that is KakaoOrder fierce the competitions of the online shopping. The KakaoOrder requires only the KakaoTalk messenger without any additional applications to order product (such as grocery, etc) and notice to the deliverer through the KakaoTalk as well.

Naver is another technology company that is originally a popular search engine in South Korea. The rising Neighborhood delivery app in the era of Covid19 force Naver to enter the competitions by enlarging their existing applications such as Naver Smart Order, Naver Neighborhood market shopping $\&$ delivery. The two existing applications are Naver native applications which are available in either web or phone based. In addition, those applications do not fully require installed-based app like the mentioned three case studies. The extension of the two applications is Naver Smart Around. The latest application was built to enter the hyperlocal delivery business without the need to install applications in the user's smartphone. This is another positive point of Naver since the three case studies are available only in Android-based smart phone. Meanwhile, Naver instant-based app is available in any operating system devices. 
Based on an experience of a delivery person, there were some limitations on the on-foot hyperlocal delivery app. First, it allowed only the distance within $1.5 \mathrm{~km}$ from the current location to the pickup location. If the distance from the pickup location to the delivery location takes place another $1.5 \mathrm{~km}$, then there could be $6 \mathrm{~km}$ after the delivery person delivered the order and return to the original (current location). Second, the weight limitation $5 \mathrm{~kg}$ is not actually more than 5 $\mathrm{kg}$ but a product which is difficult to carry with walk. For example, bringing cold food and hot food at the same time may happen. Third, the benefit is still not proper in the economic due to the less demand on weekends. In addition, the current application works well on a dense area, such as some crowd districts in Seoul capital. However, the merit is the healthy behavior due to the walking activity with some economic benefits.

\section{Conclusion}

This study explores multiple case studies of on-foot hyperlocal delivery in South Korea. The three case studies are the new rising hyperlocal delivery business model on-foot delivery. With respects to three components (strategy, customer \& market, and value added), this study explored the three case studies and provided overview to acknowledge the business model. The explained overview aligned with the aspects in the gig economy (place, routines, purpose, and people (i.e., users)). This study also provides some implycations for management and scientific approaches.

\section{Implications for Management and Practice}

Regarding the implications for management, the onfoot hyperlocal delivery overview aims to provide management understanding for logistics business in twofold: service performance and information \& value flow management. In term of service performance, the overview is expected to give understanding about the rising business model in Korea while improving the communities' participations, namely as crowdlogistics. The LML has been around in a few decades. Meanwhile, the crowd participations with on-foot delivery system has not been in the discussions on the management and practical domain. Although some business organizations have attempted to provide the similar service, the service is likely performed as selfdelivery provided by the businesses. In addition, the crowd-delivery systems have been around with the transportation mode such as motorized. The new rising on-foot hyperlocal delivery may provide insights to logistics business to innovate the services toward sustainable community development.

In the aspect of information \& value flow management, the information and communication technology (ICT) play significant role in this business model. The basis of crowd logistics is typically depending on the crowd whereby the crowd logistics provider acts as mediator. With an information and value flow, the service for the customer is likely to improve, and both the carrier and the crowd provider should see an economic benefit. Therefore, a mutually beneficial situation for both stakeholders and shareholders should be achieved.

\section{Implications for Science}

The on-foot hyperlocal delivery business model could contribute to the science in three categories: social science, transportation science, and process science. Social science is the basis of scientific theories to explain the prominence and acceptance of crowd logistics. The user behaviors knowledge extraction may provide economic-incentive models for their services. In term of transportation science, the ICTdriven theme may influence on the social behavior of the people. For example, the ICT based on location application may contribute to the communities who would like to participate in the crowd-logistics. Route optimization is another topic in the domain of transportation science. For the process science, the user trajectory may give adequate information to service providers on planning the manpower. The interdisciplinary among the three categories could contribute to the research communities in the scientific communities to provide a better monetary benefit for the business and the society.

\section{References}

1. Melendez, S. T., The Impact of Coronavirus on Last-Mile Delivery, 2020. https://www.allthingssupplychain.com/the-impact-of-coronavirus-onlast-mile-delivery/. (Accessed on December 10, 2020)

2. Huschebeck, M. and Leonardi, J., Approaching Delivery as a Service, Transportaion Research Procedia, 46, 2020, pp. 61-68.

3. Kim O. S., Parker, J. A. and Schoar, A., Revenue Collapses and the Consumption of Small Business Owners in the Early Stages of the COVD-19 Pandemic, 2020, [Online]. Available: http://www. nber.org/data-appendix/w28151.

4. Tenor, C., Hyperlocal News: After the Hype Contents Introduction, 2013.

5. Long, B., Consumers would Pay up to $16 \%$ More for Better Customer Experience, Say Companies have Lost the Human Touch, according to PwC survey,2018. http://library1.nida.ac.th/termpaper 6/sd/2554/19755.pdf.

6. Dablanc, L., Morganti, E., Arvidsson, N., Woxenius, J., Browne, M., and Saidi, N., The Rise of On-Demand 'Instant Deliveries' in European Cities, Supply Chain Forum, 18(4), 2017, pp. 203217. 
7. Dablanc, L. Rouhier, J., Lazarevic N., Klaunberg, J., Liu, Z., Koning, M., de Oliveira, L.K, Combes, F., Coulombel, N., Gardrat, M., Blanquart, C., Heitz, A., and Seidel, S., CITYLAB Observatory of Strategic Developments Impacting Urban Logistics, 4 (1), 2016, pp. 64-75, 2016, [Online]. Available:http://www.citylabproject.eu/deliverables/D2_1.pdf.

8. Okholm, H. B., Thelle, M. H., Möller, A., Basalisco, B., and Rølmer, S., E-commerce and Delivery: A Study of the State of Play of EU Parcel Markets with Particular Emphasis on ecommerce, European Commision. DirectoratGeneral for the International Market and Services, 2013 p. 297, [Online]. Available: http://ec.europa.eu/internal_market/post/doc/ studies/20130715_ce_e-commerce-and-delivery-final-report_en.pdf.

9. Milioti C., Pramatari, K. and Kelepouri, I., Modelling Consumers' Acceptance for the Click and Collect Service, Journal of Retailing and Consumer Services, 56, 2020, pp. 102-149.

10. Tripathi, S., What is a Hyperlocal Delivery Model and How does It Work?, 2020. [Online] https://cedcommerce.com/blog/what-is-a-hyperlocal-delivery-model-and-how-does-it-work/ (Accessed on December 10, 2020).

11. Madenow, A., Bauer, C., and Strauss, C., Crowdsourcing in Logistics: Concepts and Applications using the Social Crowd, 17th International Conference on Information Integration Web-Based Appl. Serv. iiWAS 2015 - Proceeding, 2015, doi: 10.1145/2837185.2837242.

12. Sampaio, A., Savelsbergh, M., Veelenturf, L., and van Woensel, T., Crowd-Based City Logistics, in
Sustainable Transportation and Smart Logistics: Decision-Making Models and Solutions, 2018.

13. Petriglieri, G., Ashford, S., and Wrzesniewski, A., Thriving in The Gig Economy, Harvard Business Review, March-April, 2018.

14. Guo, X., Lujan Jaramillo, Y. J., BloemhofRuwaard, J., and Claassen, G. D. H., On Integrating Crowdsourced Delivery in Last-mile Logistics: A Simulation Study to Quantify Its Feasibility, Journal of Cleaner Production, 241, 2019, doi: 10.1016/j.jclepro.2019.118365.

15. Rashid, Y., Rashid, A., Warraich, A., Sabir, S. S., and Waseem, A., Case Study Method: A Step-byStep Guide for Business Researchers," International Journal of Quality Methods, vol. 18, 2019.

16. Wirtz, B. W., Business Model Management. Springer, 2011.

17. Neighborhood Delivery, 2020. http://woodel.co.kr/.

18. Walking Delivery, 2020. http://www.dobo60.com/.

19. “코로나 통금’에 뜨거워진 배달시장 $\cdots \mathrm{GS} 25$. CU·이마트24 '3파전,"' 2020. http://www.sisajournal-e.com/news/articleView.html?idxno= 227086. (Accessed on December 10, 2020)

20. Das, D. and Yadav, C., A Framework of Hiring Strategy for Manpower Hiring in a Hyper-Local Food Delivery Organization, Journal of Advance Management Research, 2020, doi: 10.1108/ JAMR-06-2020-0104.

21. News Analysis, The Evolution of South Korean Convenience Stores over the 38-year History, 2020.http://english.hani.co.kr/arti/english_editio n/e_business/932615.html. (Accessed on December 10, 2020). 